\title{
An Intuitionistic Fuzzy Approach for Smart City Development Evaluation for Developing Countries: Moroccan Context
}

\author{
Mohamed Hanine ${ }^{1}\left(\mathbb{D}\right.$, Omar Boutkhoum $^{2}{ }^{\oplus}$, Fatima El Barakaz ${ }^{2}{ }^{(}$, Mohamed Lachgar $^{1}{ }^{(}$, Noureddine Assad $^{1}$, \\ Furqan Rustam ${ }^{3}$ (D) and Imran Ashraf ${ }^{4, *(D)}$ \\ 1 Department of Telecommunications, Networks, and Informatics, LTI Laboratory, ENSA, Chouaib Doukkali \\ University, El Jadida 24000, Morocco; hanine.m@ucd.ac.ma (M.H.); lachgar.m@ucd.ac.ma (M.L.); \\ assad.n@ucd.ac.ma (N.A.) \\ 2 Department of Computer Science, Faculty of Sciences, Chouaib Doukkali University, \\ El Jadida 24000, Morocco; boutkhoum.o@ucd.ac.ma (O.B.); el.barakaz.fatima@gmail.com (F.E.B.) \\ 3 Department of Computer Science, Khwaja Fareed University of Engineering and Information Technology, \\ Rahim Yar Khan, Punjab 64200, Pakistan; furqan.rustam1@gmail.com \\ 4 Department of Information and Communication Engineering, Yeungnam University, Gyeongsan 38541, Korea \\ * Correspondence: imranashraf@ynu.ac.kr
}

check for updates

Citation: Hanine, M.; Boutkhoum, O.; El Barakaz, F.; Lachgar, M.; Assad, N.; Rustam, F.; Ashraf, I. An Intuitionistic Fuzzy Approach for Smart City Development Evaluation for Developing Countries: Moroccan Context. Mathematics 2021, 9, 2668. https://doi.org/10.3390/math9212668

Academic Editors: James Liou and Artūras Kaklauskas

Received: 17 September 2021

Accepted: 18 October 2021

Published: 21 October 2021

Publisher's Note: MDPI stays neutral with regard to jurisdictional claims in published maps and institutional affiliations.

Copyright: (C) 2021 by the authors. Licensee MDPI, Basel, Switzerland. This article is an open access article distributed under the terms and conditions of the Creative Commons Attribution (CC BY) license (https:// creativecommons.org/licenses/by/ $4.0 /)$.

\begin{abstract}
Rapid urbanization to meet the needs of the growing population has led to several challenges such as pollution, increased and congested traffic, poor sustainability, and impact on the ecological environment. The conception of smart cities comprising intelligent convergence systems has been regarded as a potential solution to overcome these problems. Based on the information, communications, and technology (ICT), the idea of a smart city has emerged to decrease the impact of rapid urbanization. In this context, important efforts have been made for making cities smarter and more sustainable. However, the challenges associated with the implementation and evaluation of smart cities in developing countries are not examined appropriately, particularly in the Moroccan context. To analyze the efficacy and success of such efforts, the evaluation and comparisons using common frameworks are significantly important. For this purpose, the present research aims to investigate and evaluate the most influential dimensions and criteria for smart city development (SCD) in the Moroccan context. To reach this goal, this study proposes a new integrated Multi-Criteria Decision-Making (MCDM) model based on Intuitionistic Fuzzy Analytical Hierarchy Process (IFAHP) and Intuitionistic Fuzzy Decision-Making Trial and Evaluation Laboratory (IF-DEMATEL). In the given context, the IF-AHP is employed to analyze the structure of the problem and calculate the weights of the qualitative and quantitative dimensions/criteria by incorporating the uncertainty values provided by the experts. Later, IF-DEMATEL is used to construct the structural correlation of dimensions/criteria in MCDM. The use of intuitionistic fuzzy set theory helps in dealing with the linguistic imprecision and the ambiguity of experts' judgment. Results reveal that 'Smart Living and Governance' and 'Smart Economy' are major dimensions impacting the SCD in the Moroccan context. The proposed model focuses on enhancing the understanding of different dimensions/criteria and situations in smart cities compared to traditional cities and elevates their decision-making capability. Moreover, the results are discussed, as are the managerial implications, conclusions, limitations, and potential opportunities.
\end{abstract}

Keywords: smart city development; multicriteria decision making; intuitionistic fuzzy set; analytical hierarchy process; DEMATEL

\section{Introduction}

During the past three decades, the world population has been increased by approximately $50 \%$, from 5.28 billion in 1990 to 7.753 billion in 2020 [1]. Consequently additional infrastructure for living, traveling, working, health, and education is required. Lack of proper infrastructure in villages, especially in developing countries, leads to a higher 
migration of a large number of people to urban zones. Forecasts show that approximately $60 \%$ of the citizens will be populated in urban areas by 2030 and this percentage will rise to $75 \%$ by 2050 [2,3]. Industry development, urban development, and global growth have been regarded as three significant factors for the continuation of human civilization. Because of the increasing population worldwide, rapid urbanization and migration towards cities have been increased substantially during the past few decades. Such transformation brought several problems, such as inappropriate public transportation, weak sustainability, pollution, low security, and slow enterprise production, etc. [4]. These problems require cities to engage resources to overcome these challenges and improve the quality of life of their citizens [5]. Resolving these issues necessitates innovative solutions and advanced techniques in urban planning and conception [6]. Among the proposed concepts for dealing with urbanization, smart city development has gained wide attraction. Smart cities can be operationalized by smart technology where computing technology is foreseen to be in almost every object [7]. Such implementation assists in enhancing the quality of the services and improving the living conditions.

Smart cities are deemed as prospective for the evolution and growth of a country's economy [8]. The concept of the smart city has attracted significant attention for the past two decades. Consequently, a multitude of concepts explaining the vision of the smart city can be found in the literature [9]. Furthermore, the redevelopment of classical cities as smart cities gained global attention when IBM presented its vision of smart cities in 2009 [10]. As a result, China started the design and development of approximately 100 smart cities in 2010 [11]. Similarly, the Indian government launched a project called "100 Smart Cities Mission" for sustainable smart city development (SCD) in 2015 [12]. A novel strategy for SCD is adopted by Taiwan where a smart city project is started in Taipei to overcome rapid urbanization and provide better services to the citizens [13]. Another project is initiated by the Korea Research Institute for Humans Settlements (KRIHS) in association with the Inter-American Development Bank (IDB) to construct a new smart city near Seoul with a vision to become the Silicon Valley of Korea [14].

The developing countries are striving to choose the SCD strategies of the developed economies for effective and efficient SCD implementation [15]. However, such adaptation is not straightforward due to prevailing social and economic conditions, as well as, the technological capabilities to accomplish this task [16]. Therefore, the developing countries must contrive the outlines of a framework that could help and support the efficient development of smart cities [17]. Several works pointed out various dimensions to support SCD such as smart industry, resourceful environment, sustainability, advanced technology, economic management, and government $[12,18,19]$.

Similarly, the authors present the improvement of sustainability levels using the smart city initiatives in India [20]. Ibrahim et al. introduce essential elements of a smart city which are helpful to attain sustainability [21]. However, a structured framework for smart city adoption is not described. Despite the proposals and descriptions of different elements and a group of dimensions for SCD [22-24], no framework is available for guiding decision-makers and policymakers for adopting SCD in developing countries. The same issue is raised in [25], where the authors point out that the literature on the smart city lacks a framework to support and help policymakers from developing countries to implement SCD. Therefore, the present study is an attempt to bridge the gap by proposing a novel framework that could help and support policymakers in the adoption of the smart city.

For developing countries, particularly for Morocco, the prime SCD initiative has been proposed by a partnership between Wilaya of Grand Casablanca, the region of Grand Casablanca, and the Federation of Information Technology, Telecommunications and Offshoring (APEBI) in 2015 and named as "E-Madina the smart city cluster" [26]. The essential elements of SCD include:

- Resources management,

- Sustainability,

- E-governance, 
- Smart living,

- Smart mobility,

- Information \& Communication Technology (ICT),

- Security system,

- Smart people.

The main goal of this study is to improve the perception of requirements necessary for SCD. In particular, SCD research and analysis are in the early stages in developing countries, and additional qualitative and quantitative analyses are needed to fully grasp the concept.

Thereby, a framework to assist policymakers in an SCD project in the Moroccan context is presented in this research. To reach this goal, the current study proposes a novel framework based on multi-criteria decision making (MCDM) for exploring the influential relationships and degrees of influence among various dimensions/criteria of a smart city. All existing works with focus on the development and/or evaluation of the main dimensions affecting SCD have used a diversity of MCDM methods [12,13,19,27-34].

However, to the best of the authors' knowledge, this work is a first attempt at using the AHP and DEMATEL approaches under uncertainty consideration by using the Intuitionistic Fuzzy Set (IFS) in the Moroccan context as a developing country. In this context, this study makes the following contributions:

- A hybrid framework is proposed that utilizes Intuitionistic Fuzzy AHP (Analytical Hierarchy Process) and Intuitionistic Fuzzy DEMATEL (Decision-Making Trial and Evaluation Laboratory) approaches.

- The Moroccan context is used as a developing country, where the specified dimensions/criteria for SCD are identified by experts. The discovered dimensions are further analyzed using the proposed framework.

- The importance and causal relationships between the dimensions/criteria for smart city framework development are investigated using Intuitionistic Fuzzy DEMATEL. The weights of the selected dimensions/criteria are computed and structured by applying Intuitionistic Fuzzy AHP.

The rest of this research is structured as follows. In Section 2, the literature review is presented, which is divided into two sub-divisions: dimensions and applications of smart cities and MCDM approaches applied in SCD. The proposed methodology is illustrated in Section 3. Section 4 describes the development of the methodology in a case application. The result and discussion are given in Section 5. Section 6 presents the conclusion, future trends, and implications of this study.

\section{Literature Review}

Given the increased interest in the smart city concept during the last few years, several research works can be found in the literature that describes different dimensions of the SCD concept. Therefore, the objective of this section is to illustrate the applications, benefits, and approaches applied in SCD.

\subsection{Dimensions and Applications of Smart City}

Giffinger et al. proposed four dimensions of smart cities in [35] including the economy, people, education, and infrastructure. These are extended by the Vienna University of Technology to 6 main dimensions which are smart mobility, smart economy, smart governance, smart people, smart living, and smart environment. The last three dimensions influence the quality of life according to [36]. Improving the quality of life has been regarded as an important dimension in several other works as well. For example, Shapiro et al. specified the essential dimensions of a smart city including administration, human, and technology [37]. Similarly, the authors in [38] point out ICT, economic expansion, employment increase, and improving the quality of life as the essential dimensions of smart cities. The study [39] describes sustainability, quality of life, society, industry, and environmental goals as the important dimensions. According to [40], environmental 
factors, society, people, industry, and public administration are the essential dimensions of smart cities. Regarding [3], the principal dimensions for smart cities include economy, human, e-government, ICT, industry, built infrastructure, and environment.

Over the past several years, smart city implementations have been established via diverse models aiming to improve the quality of life for citizens [27]. The application fields of smart cities are sustainability, transport, pollution, health, economy, and administration. The prime society which suggested the model for a smart city is Cisco, and it is utilized in Dubai [41]. The last model included a healthcare city, smart public administration, a smart media city, and a city of technology. IBM is the second society that suggested a novel model for the smart city which is implemented in New York City, US. Also, Siemens suggested a model for smart cities in Germany [42] and another model is applied in Montreal as well [43]. All of the smart city models discussed here share the same smart dimensions including transport, environment, industry, government, and humans [44].

In brief, the effective implementation of a smart city depends on how a city is financed, designed, and exploited. Most of the existing studies concentrate on specifying the scope and application of the smart city. Only a few studies have developed a process to help policymakers, especially in developing countries, understand and analyze the potential and actual resources for SCD. Moreover, the sustainability of several urban services depends mainly on perfect and complete data used in the analysis and evaluation of the essential criteria for SCD. Generally, the source of data/information in smart cities is multifarious and may include uncertain, imprecise, and/or ambiguous data which reduces its full potential. To fill the shortcomings of data, various models have been suggested based on the probability theory [45] for handling incomplete data, the possibility theory [46] for handling imprecise data, and the bipolar logic [47] and rough sets [48] for handling imprecise data. For handling vagueness and imprecision, the fuzzy sets theory has been suggested. Nevertheless, the intuitionistic fuzzy set theory is a powerful tool for handling several types of imprecision and ambiguity [49].

\subsection{Multi Criteria Decision Making Approaches for Smart City Development}

Complicated issues considering a wide number of factors are resolved by integrating MCDM methodologies. Diverse issues associated with SCD have also been investigated using MCDM methodologies. For example, the authors analyze various problems of SCD for urban areas using the Analytical Network Process (ANP) and DEMATEL approach in [28]. Hashemkhani et al. use an integrated SWARA-COPRAS methodology for assessing construction projects to reach environmental sustainability [29]. The study [27] proposes a hybrid MCDM approach based on ANP and TOPSIS for the evaluation of smart sustainable cities. Katal et al. [30] establish an optimized energy planning system through priority analysis and assessing various types of old power plants by using the VIKOR technique for sustainable development. A framework is also suggested for reaching sustainability in construction projects to assist SCD. [31] uses the Fuzzy AHP for evaluating the green technology incorporated in old and new infrastructures.

Several studies prefer AHP and ANP over other MCDM methods for calculating the criteria weight and defining the priorities. DEMATEL and AHP have been used and found favorable in multiple domains including modeling and evaluating the smart city performance, developing models for smart cities [27], the evaluation of ubiquitous cities [28], and smart city project selection [13]. Similarly, AHP and ANP are applied to real case studies for planning smart cities [32], data acquisition and ubiquitous communication provisioning in smart cities [33], and evaluation of the livability levels of metropolitan cities [34].

Recently, several studies integrate MCDM with mathematical programming (MP) methods or artificial intelligence (AI) techniques for resolving many problems related to smart cities. For smart city projects, MP approaches are used to develop data aggregation and service creation [50,51]. MP approaches can also help with energy efficiency assessments and optimization $[52,53]$ and geographic data infrastructure initiatives $[54,55]$. Aside from 
that, $\mathrm{AI}$ approaches can solve significant degrees of complexity in modeling. For example, in the industrial system, AI algorithms swiftly evaluate operational data to generate new insights and improve decision-making [56], or several social science theories of human behavior [57]. In general, various studies have been carried out on smart city strategies in many countries. Table 1 summarizes recent literature about smart cities, including references, methodologies used, and objectives.

The selection of an MCDM method is based on the type of the issue and required results [58]. These methods are used for weight calculation, ranking, and structuring objectives, etc. For the current study, three objectives are to be realized. Firstly, the most important dimensions and criteria influencing the evaluation of SCD in the Moroccan context should be structured. Secondly, the weight of the selected dimensions/criteria should be computed. Lastly, the imprecise and ambiguity of judgment on account of experts should be considered and incorporated. Given the objectives of the study, the DEMATEL method appears the best alternative to solve the problem where powerful interrelationships exist in a wide range of dimensions/criteria [28,59]. On the other end, for computing the weights of each dimension/criterion, the AHP method has been regarded as an important choice. Finally, to handle imprecision and ambiguity of data, the intuitionistic fuzzy set theory (IFS) is a strong tool. Hence, a hybrid Intuitionistic Fuzzy AHP - Intuitionistic Fuzzy DEMATEL approach is used to reach the defined goals.

Table 1. A brief summary of discussed works on smart city development.

\begin{tabular}{|c|c|c|}
\hline Reference & Methodology & Objective \\
\hline [13] & AHP and ZOGP & Developed a decision approach to assess and select projects of smart city \\
\hline [27] & ANP and TOPSIS & Evaluated the actual smart sustainable cities through the MCDM Framework \\
\hline [34] & DEMATEL and ANP & Examined the livability levels of metropolitan cities \\
\hline [33] & TOPSIS & $\begin{array}{l}\text { Presented an empirical study for data acquisition and ubiquitous communication } \\
\text { provisioning in smart cities }\end{array}$ \\
\hline [28] & ANP and DEMATEL & $\begin{array}{l}\text { Analyzed various indicators for assessment of ubiquitous cities via a methodological } \\
\text { framework }\end{array}$ \\
\hline [30] & VIKOR & $\begin{array}{l}\text { Optimized energy planning system through priority analysis and assessing various } \\
\text { types of old power plants }\end{array}$ \\
\hline [29] & SWARA-COPRAS & $\begin{array}{l}\text { Provided a new approach for assessing the construction projects to reach environmental } \\
\text { sustainability }\end{array}$ \\
\hline [11] & VIKOR, ANP and DEMATEL & $\begin{array}{l}\text { Determined the relationship between criteria used in a galactic model, and compared the } \\
\text { Chinese cities }\end{array}$ \\
\hline [60] & TOPSIS, ANP and SE & $\begin{array}{l}\text { Provided an approach for investigating the application of SOAR and PESTLE } \\
\text { frameworks for managing air pollution }\end{array}$ \\
\hline [61] & TOPSIS and EVA & $\begin{array}{l}\text { Evaluated and prioritized smart city product-service systems by using a MCDM } \\
\text { framework in Italy }\end{array}$ \\
\hline [62] & $\mathrm{AHP}$ and ANP & $\begin{array}{l}\text { Described and analyzed alternative city models using an MCDM approach to dealing } \\
\text { with complex decisions }\end{array}$ \\
\hline [63] & AHP and GIS & $\begin{array}{l}\text { Proposed an integrated approach (GIS-AHP) to support planners in determining, } \\
\text { quantifying, and visualizing land in South Africa }\end{array}$ \\
\hline [64] & MAUT & $\begin{array}{l}\text { Presented an empirical study for specifying and prioritizing difficulties in the } \\
\text { implementation of smart energy city projects in Europe }\end{array}$ \\
\hline [65] & TOPSIS and Neural Network & $\begin{array}{l}\text { Evaluated various aspects of air pollutants to model the influence of air pollution on the } \\
\text { urban economic }\end{array}$ \\
\hline [31] & Fuzzy AHP & $\begin{array}{l}\text { Presented an empirical review and a case study to evaluate the building green } \\
\text { technologies to develop smart city performance }\end{array}$ \\
\hline [66] & AHP, Fuzzy Delphi and DEA & Integrated smart growth principles into the urban transportation planning \\
\hline [19] & Fuzzy Logic Model & Computing the smart city indices for European cities \\
\hline
\end{tabular}

The discussed literature indicates the need for an approach to guide policymakers for SCD. In this regard, the current study attempts to determine the intensity of dimensions and 
expose the inter-relations among the dimensions for successful SCD in a developing country context through combined IF-AHP and IF-DEMATEL. So the current study is aligned with the need of evaluating SCD dimensions and relationships in the developing countries.

\section{Proposed Research Methodology}

Figure 1 shows the architecture of the proposed methodology. An extensive literature review is conducted in the first step to extract the most essential dimensions and criteria that drive the SCD projects. Initially, the research documents that report on SCD dimensions are chosen and an Excel spreadsheet is created. Then, the list is forwarded to the expert groups. This study employs questionnaires filled out by many experts in several domains including environment, information technology, and departmental elected officials. The experts are asked to compare the validity, as well as, the strength of interrelationships between selected criteria. After that, the IF-AHP is used to perform a structural framework and employed to calculate the priorities or influence strength (Weights) of the shortlisted dimensions/criteria. Moreover, an IF-DEMATEL analysis is performed to determine the driving power and dependence of dimensions in the framework. Using the DEMATEL technique, a dimensions' relationship network is generated for the MCDM process. This technique can successfully examine relations, both direct and indirect, between dimensions of a system concerning the type and complexity of the system.

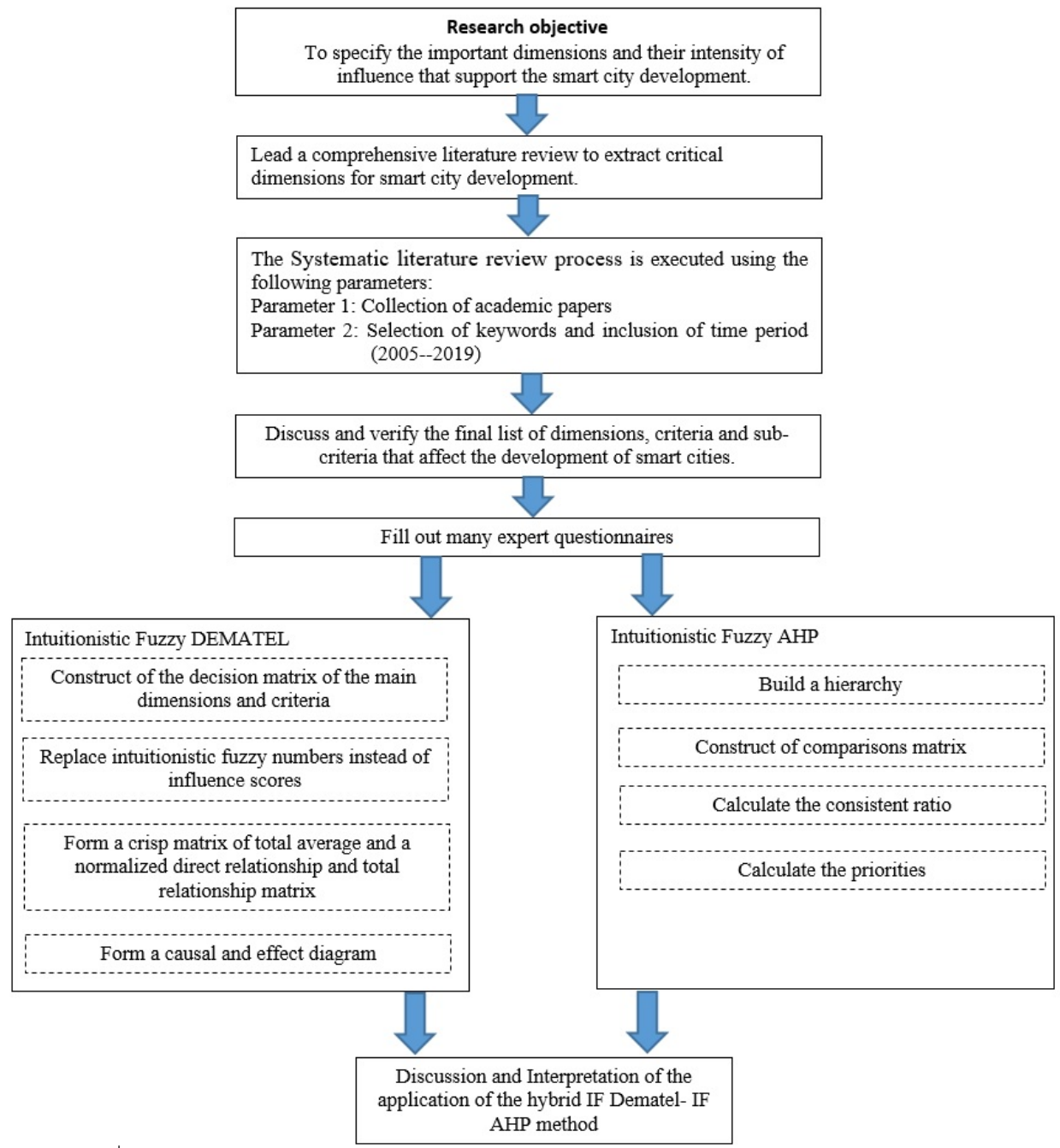

Figure 1. Architecture of the proposed methodology. 


\subsection{IF-AHP and IF-DEMATEL Approach}

\subsubsection{Intuitionistic Fuzzy Set Theory}

In 1965, Zadeh proposed the fuzzy sets theory, which followed Atanassov's novel proposal of intuitionistic fuzzy set theory of $1986[67,68]$. Trapezoidal intuitionistic fuzzy numbers (TrIFNs) by Nehi and Maleki can be generated by extending intuitionistic triangular fuzzy numbers (ITFNs) [69]. The two intuitionistic fuzzy numbers (trapezoidal and triangular) are the generalization of the intuitionistic fuzzy set, generating a continuous set from a discrete one [70]. A membership function and a non-membership function describe Intuitionistic fuzzy set (IFS) theory. When compared to fuzzy sets theory, which does not consider the hesitation degree of decision-makers, IFSs have shown clear advantages for dealing with ambiguity and uncertainty [71]. The following are the key benefits of IFSs: [72-75]:

- IFSs can be used to model unknown data by using different degrees of hesitation. Therefore, in practical cases when the decision-makers are unsure about their judgments, IFSs should be preferred over fuzzy sets to obtain the opinions.

- IFSs can represent three different types of membership functions: membership, nonmembership, and hesitancy. Thereby, it is similar to a type 2 fuzzy set, although all types of fuzzy numbers just reflect one level of membership which is a crisp integer in the interval $[0,1]$.

- All fuzzy numbers can just indicate the ambiguity of 'agreement' but they can't depict the expert's 'disagreement'. Generally, IFSs take into account judgment or preferences from three perspectives to assure that the preferences are more completely considered.

The definitions and concepts of intuitionistic fuzzy set theory which are important to understand the proposed framework, are discussed below [76]:

Definition 1. Let $F$ be a fixed set, then an IFS A in $F$ is defined as:

$$
A=\left\{\left(f, \mu_{A}(f), v_{A}(f)\right) \mid f \in F\right\}
$$

where $\mu_{A}(f):(F) \rightarrow[0,1]$ and $v_{A}(f):(F) \rightarrow[0,1]$ are defined such that $0 \leq \mu_{A}(f)+v_{A}(f) \leq$ ,$f \in F$. The number $\mu_{A}(f)$ indicates membership degree and $v_{A}(f)$ denotes non-membership degree of element $f \in F$ to set $A$. The $\pi_{A}(f)$ is hesitance level of $f \in F$ to $A$ and $0 \leq \pi_{A}(f) \leq 1, f \in F$ which are calculated according using Equation (1), can be calculated using Equation (2) [68]:

$$
\pi_{A}(f)=1-\mu_{A}(f)-v_{A}(f), \quad f \in F
$$

Definition 2. A trapezoidal intuitionistic fuzzy number $A$ with parameters $b_{1} \leq a_{1} \leq b_{2} \leq a_{2} \leq$ $a_{3} \leq b_{3} \leq a_{4} \leq b_{4}$ is represented by $A=\left\{\left(a_{1}, a_{2}, a_{3}, a_{4}\right),\left(b_{1}, b_{2}, b_{3}, b_{4}\right)\right\}$ in $R$ which is a set of real numbers. The Equations (3) and (4) can be used for obtaining the membership and non-membership functions of $A$.

$$
\begin{gathered}
\mu_{A}(f)= \begin{cases}0 & f<a_{1} \\
\frac{f-a_{1}}{a_{2}-a_{1}} & a_{1} \leq f \leq a_{2} \\
1 & a_{2} \leq f \leq a_{3} \\
\frac{f-a_{4}}{a_{3}-a_{4}} & a_{3} \leq f \leq a_{4} \\
0 & a_{4}<f\end{cases} \\
v_{A}(f)= \begin{cases}1 & f<b_{1} \\
\frac{f-b_{2}}{b_{1}-b_{2}} & b_{1} \leq f \leq b_{2} \\
1 & b_{2} \leq f \leq b_{3} \\
\frac{f-b_{3}}{b_{4}-b_{3}} & b_{3} \leq f \leq b_{4} \\
0 & b_{4}<f\end{cases}
\end{gathered}
$$


Let $b_{2}=b_{3}$ and $a_{2}=a_{3}$ be in a trapezoidal intuitionistic fuzzy numbers $A$, then it changes to triangular IFNs. Let $A_{1}=\left\{\left(a_{1}, a_{2}, a_{3}, a_{4}\right),\left(b_{1}, b_{2}, b_{3}, b_{4}\right)\right\}$ and $A_{2}=\left\{\left(c_{1}, c_{2}, c_{3}, c_{4}\right),\left(d_{1}, d_{2}, d_{3}, d_{4}\right)\right\}$ be trapezoidal intuitionistic fuzzy numbers and $k>0$ according to [69] the following properties (Equations (5) and (6)) are correct:

$$
\begin{gathered}
A_{1}+A_{2}=\left\{\left(a_{1}+c_{1}, a_{2}+c_{2}, a_{3}+c_{3}, a_{4}+c_{4}\right),\left(b_{1}+d_{1}, b_{2}+d_{2}, b_{3}+d_{3}, b_{4}+d_{4}\right)\right\} \\
k A_{1}=\left\{\left(k a_{1}, k a_{2}, k a_{3}, k a_{4}\right),\left(k b_{1}, k b_{2}, k b_{3}, k b_{4}\right)\right\}
\end{gathered}
$$

Theorem 1. Let $A=\left\{\left(a_{1}, a_{2}, a_{3}, a_{4}\right),\left(b_{1}, b_{2}, b_{3}, b_{4}\right)\right\}$ be a trapezoidal intuitionistic fuzzy numbers in (set of real numbers). According to Equation (7) expected value is calculated when $b_{1} \leq a_{1} \leq$ $b_{2} \leq a_{2} \leq a_{3} \leq b_{3} \leq a_{4} \leq b_{4} \in R$.

$$
E V(A)=\frac{1}{8}\left(a_{1}+a_{2}+a_{3}+a_{4}+b_{1}+b_{2}+b_{3}+b_{4}\right)
$$

\subsubsection{Intuitionistic Fuzzy DEMATEL (IF-DEMATEL)}

DEMATEL is a technique for creating structural models that contain causal relationships among complex factors. The Battelle Memorial Institute in Geneva presented the DEMATEL technique for science and human affairs to handle complex and interconnected problems [75]. All factors in DEMATEL are divided into cause and effect groups and these groups are generated by combining the influence values between factors. This classification allows a better understanding of the components of the system to find solutions for problems [59]. The steps carried out in the IF-DEMATEL method are as follows [77]:

- Creating a direct-relation matrix: Experts generate a direct-relation matrix $\mathrm{A}_{(n \times n)}(n$ is the total number of criteria) by performing pairwise comparisons between criteria using the scale depicted in Table 2. Each member of matrix $\mathrm{A}_{(n \times n)}$ is represented by $a_{i j}$ number which specifies the impact level of criterion $i$ on $j$. The $n \times n$ averaged matrices $A$ for all experts' judgments are computed as:

$$
a_{i j}=\frac{\sum_{k=1}^{H} F_{i j}^{k}}{H}
$$

where $H$ represents the total number of experts

- Computing the normalized matrix of initial direct relations by using Equations (9) and (10):

$$
\begin{gathered}
F=k \cdot A \\
k=\frac{1}{\max _{1 \leq i \leq n} \sum_{j=1}^{n} a_{i j}}
\end{gathered}
$$

- Developing a total relation matrix $T$ using Equation (11). The identity matrix is represented by $I$.

$$
T=F(I-F)^{-1}
$$

- Establishing a causal diagram. $D$ and $R$ which represent the total number of rows and total number of columns, respectively are calculated using Equations (12)-(14):

$$
\begin{gathered}
T=\left[t_{i j}\right]_{n \times n} \quad i, j=1,2, \ldots, n \\
R=\left[\sum_{i=1}^{n} t_{i j}\right]_{1 \times n}^{t}=\left[t_{j}\right]_{1 \times n} \\
D=\left[\sum_{j=1}^{n} t_{i j}\right]_{n \times 1}=\left[t_{i}\right]_{n \times 1}
\end{gathered}
$$


where $(D+R)$ represents the total effects and the relative importance of each criterion (horizontal axis). The $(D-R)$ represents the net effect of each criterion (vertical axis). Generally, a criterion appears in the cause group if $(D-R)$ is a positive value, and in the case of negative, the criterion is classified in the effect category.

Table 2. Linguistic expressions values of Trapezoidal fuzzy numbers for linguistic terms [Adapted from [74]].

\begin{tabular}{ccccc}
\hline Linguistic Expressions & Acronyms & Influence Score & Trapezoidal IF Numbers Expected & Crisp Value \\
\hline Absolutely Low Influence & ALI & 0 & $((0 ; 0 ; 0 ; 0) ;(0 ; 0 ; 0 ; 0))$ & 0 \\
\hline Low Influence & LI & 1 & $((0 ; 0,1 ; 0,2 ; 0,3) ;(0 ; 0,1 ; 0,2 ; 0,3))$ & 0,15 \\
\hline Fairly Low Influence & FLI & 2 & $((0,1 ; 0,2 ; 0,3 ; 0,4) ;(0 ; 0,2 ; 0,3 ; 0,5))$ & 0,25 \\
\hline Medium Influence & MI & 3 & $((0,3 ; 0,4 ; 0,5 ; 0,6) ;(0,2 ; 0,4 ; 0,5 ; 0,7))$ & 0,45 \\
\hline Fairly High Influence & FHI & 4 & $((0,5 ; 0,6 ; 0,7 ; 0,8) ;(0,4 ; 0,6 ; 0,7 ; 0,9))$ & 0,65 \\
\hline High Influence & HI & 5 & $(0,7 ; 0,8 ; 0,9 ; 1) ;(0,7 ; 0,8 ; 0,9 ; 1))$ & 0,85 \\
\hline Absolutely High Influence & AHI & 6 & $((1 ; 1 ; 1 ; 1) ;(1 ; 1 ; 1 ; 1))$ & 1 \\
\hline
\end{tabular}

3.1.3. Intuitionistic Fuzzy Analytic Hierarchy Process Technique

A hierarchy is an effective way of classifying systems used to organize the information obtained from experience or reflection. Using the hierarchical structure, the complexity of the world around us can be understood in terms of the order and distribution of influence that provides certain numerical results [78]. IFS is integrated with the classical AHP in this study, considering the limiting capability of expressing a judgment precisely and the advantages of IFS to present the degree of membership and non-membership at the same time. The steps of the IF-AHP method are detailed below as outlined in [73].

- After the construction of the hierarchy model of the problem, the IFS matrices are established by taking into account the $k$ experts and $n$ dimensions/criteria. The importance judgment of the experts is described by the linguistic expressions given in Table 3 . The decision-making matrix by the $k$ expert is illustrated in Equation (15):

$$
R^{(k)}=\left(r_{i j}^{(k)}\right)_{n \times n}=\left(\begin{array}{cccc}
r_{11}^{(k)} & r_{12}^{(k)} & \ldots & r_{1 n}^{(k)} \\
r_{21}^{(k)} & r_{22}^{(k)} & \ldots & r_{2 n}^{(k)} \\
\cdot & \cdot & & \cdot \\
\cdot & \cdot & & \cdot \\
\cdot & \cdot & & \cdot \\
r_{n 1}^{(k)} & r_{n 2}^{(k)} & \ldots & r_{n n}^{(k)}
\end{array}\right)
$$

where $r_{i j}^{(k)}=\left(\mu_{i j}^{(k)}, v_{i j}^{(k)}, \pi_{i j}^{(k)}\right)$

Table 3. Intuitionistic fuzzy numbers and corresponding linguistic terms for pairwise comparison.

\begin{tabular}{ccc}
\hline Linguistic Expressions & Acronyms & IFNs \\
\hline Extreme low & $\mathrm{EL}$ & $(0.05,0.95,0.0)$ \\
Very low & $\mathrm{VL}$ & $(0.15,0.8,0.05)$ \\
Low & $\mathrm{L}$ & $(0.25,0.65,0.1)$ \\
Medium low & $\mathrm{ML}$ & $(0.35,0.55,0.1)$ \\
Medium & $\mathrm{M}$ & $(0.5,0.4,0.1)$ \\
Medium high & $\mathrm{MH}$ & $(0.65,0.25,0.1)$ \\
High & $\mathrm{H}$ & $(0.75,0.15,0.1)$ \\
Very high & $\mathrm{VH}$ & $(0.85,0.1,0.05)$ \\
Extreme high & $\mathrm{EH}$ & $(0.95,0.05,0)$ \\
\hline
\end{tabular}


- Let $E_{k}=\left[u_{k}, v_{k}, \pi_{k}\right]$ be an intuitionistic fuzzy number for the assessment of the $k$ expert (see Table 4 ) and $\lambda_{k}$ be the importance weights of the experts, the weight of the $k$ expert can be calculated by using Equation (16) [79].

$$
\lambda_{k}=\frac{\mu_{k}+\pi_{k}\left(\frac{\mu_{k}}{\mu_{k}+v_{k}}\right)}{\sum_{k=1}^{t}\left(\mu_{k}+\pi_{k}\left(\frac{\mu_{k}}{\mu_{k}+v_{k}}\right)\right)}
$$

where $\sum_{k=1}^{t} \lambda_{k}=1, \lambda_{k} \in[0,1]$

- Develop the aggregated IFS matrix according to all experts' judgments and preferences. To do this, an intuitionistic fuzzy weighted averaging (IFWA) operator suggested by [73] is employed (Equation (17)). Let $R^{(k)}=\left(r_{i j}^{(k)}\right)$ be an IFS decision matrix of the $k$ experts,

$$
\begin{aligned}
r_{i j} & =I F W A_{\lambda}\left(r_{i j}^{(1)},\left(r_{i j}^{(2)}, \ldots,\left(r_{i j}^{(t)}\right)=\lambda_{1}\left(r _ { i j } ^ { ( 1 ) } \oplus \lambda _ { 2 } \left(r_{i j}^{(2)} \oplus \ldots \lambda_{t}\left(r_{i j}^{(t)}\right)=\right.\right.\right.\right. \\
& =\left(1-\prod_{k=1}^{t}\left(1-\mu_{i j}^{(k)}\right)^{\lambda_{k}}, \prod_{k=1}^{t}\left(1-v_{i j}^{(k)}\right)^{\lambda_{k}}, \prod_{k=1}^{t}\left(1-\mu_{i j}^{(k)}\right)^{\lambda_{k}}-\prod_{k=1}^{t}\left(1-v_{i j}^{(k)}\right)^{\lambda_{k}}\right)
\end{aligned}
$$

The aggregated IF decision matrix can be presented in Equation (18):

$$
R=\left(\begin{array}{cccc}
r_{11} & r_{12} & \ldots & r_{1 n} \\
r_{21} & r_{22} & \ldots & r_{2 n} \\
\cdot & \cdot & & \cdot \\
\cdot & \cdot & & \cdot \\
\cdot & \cdot & & \cdot \\
r_{n 1} & r_{n 2} & \ldots & r_{n n}
\end{array}\right)
$$

where $r_{i j}=\left(\mu_{i j}, v_{i j}, \pi_{i j}\right)$,

$\mu_{i j}=1-\prod_{k=1}^{t}\left(1-\mu_{i j}^{(k)}\right)^{\lambda_{k}}, v_{i j}=\prod_{k=1}^{t}\left(1-v_{i j}^{(k)}\right)^{\lambda_{k}}, \pi_{i j}=\prod_{k=1}^{t}\left(1-\mu_{i j}^{(k)}\right)^{\lambda_{k}}-\prod_{k=1}^{t}(1-$ $\left.v_{i j}^{(k)}\right)^{\lambda_{k}}, \quad i, j \in N$

- Calculate the IF entropy weights of the dimension/criteria based on Equations (19) and (20)

$$
H_{j}=-\frac{1}{n \ln 2} \sum_{i=1}^{n}\left[\mu_{i j} \ln \mu_{i j}+v_{i j} \ln v_{i j}-\left(1-\pi_{i j}\right) \ln \left(1-\pi_{i j}\right)-\pi_{i j} \ln 2\right]
$$

Then $W$ can be computed as below

$$
W_{j}=\frac{1-H_{j}}{n-\sum_{j=1}^{n} H_{j}}
$$

Table 4. Linguistic expressions to assess the importance weights of expert.

\begin{tabular}{cc}
\hline Linguistic Expressions & IFNs $(\mu, v, \pi)$ \\
\hline Very important & $(0.9,0.05,0.05)$ \\
Important & $(0.75,0.2,0.05)$ \\
Medium & $(0.5,0.4,0.1)$ \\
Unimportant & $(0.25,0.6,0.15)$ \\
Very unimportant & $(0.1,0.8,0.1)$ \\
\hline
\end{tabular}




\section{Application of the Proposed Methodology}

For achieving the goal of SCD evaluation in the Moroccan context, the proposed research framework is implemented in three stages. The description of each stage is presented in the following

Stage I: is the specification of dimensions/criteria with high impact on SCD in the Moroccan context from existing literature resources and data collection. To illustrate the applicability of the present work, this study considers the cases of smart city development in Morocco. In various states, a total of 4 cities (Casablanca, Marrakesh, Rabat, and Tangier) will be developed as smart cities [80,81]. The Moroccan government and policymakers are struggling to analyze and understand the most critical factors related to SCD. Also, a structured decision-making framework has to be adopted to make Morocco's smart city initiatives sustainable. For assessing the problem, this study establishes an expert group consisting of four experts. Several questionnaires are used to take the input from the experts. Experts are asked to compare the validity of different dimensions/criteria, as well as, determine the strength of the interrelationships between the defined dimensions/criteria.

The purpose of the questionnaire survey is to get expert opinions on SCD. The questionnaire is created for data gathering and contains a list of dimensions identified from a thorough literature review. Then, each expert is provided a full explanation of the research's purpose and utility before the data collection. Afterward, the experts are asked to evaluate the dimensions/criteria with high influence on SCD by using a linguistic expression as indicated in Tables 2 and 3.

This part of the application starts with the identification of 23 criteria impacting SCD in the context of developing countries. These criteria are extracted from the literature review and other available documents about smart cities [82] as shown in Table 5. The 23 identified criteria are broadly categorized under five principal dimensions, including smart environment (SEn), smart people (SPe), smart mobility (Transportation and ICT) (SMo), smart economy (SEc), and smart living and governance (SLG) through experts' inputs. Figure 2 shows the grouping of smart city dimensions/criteria (five principal dimensions and 23 criteria) to calculate their priorities (weights) via IF-AHP. The essential foundation for grouping is meaningful correlations between the dimensions/criteria.

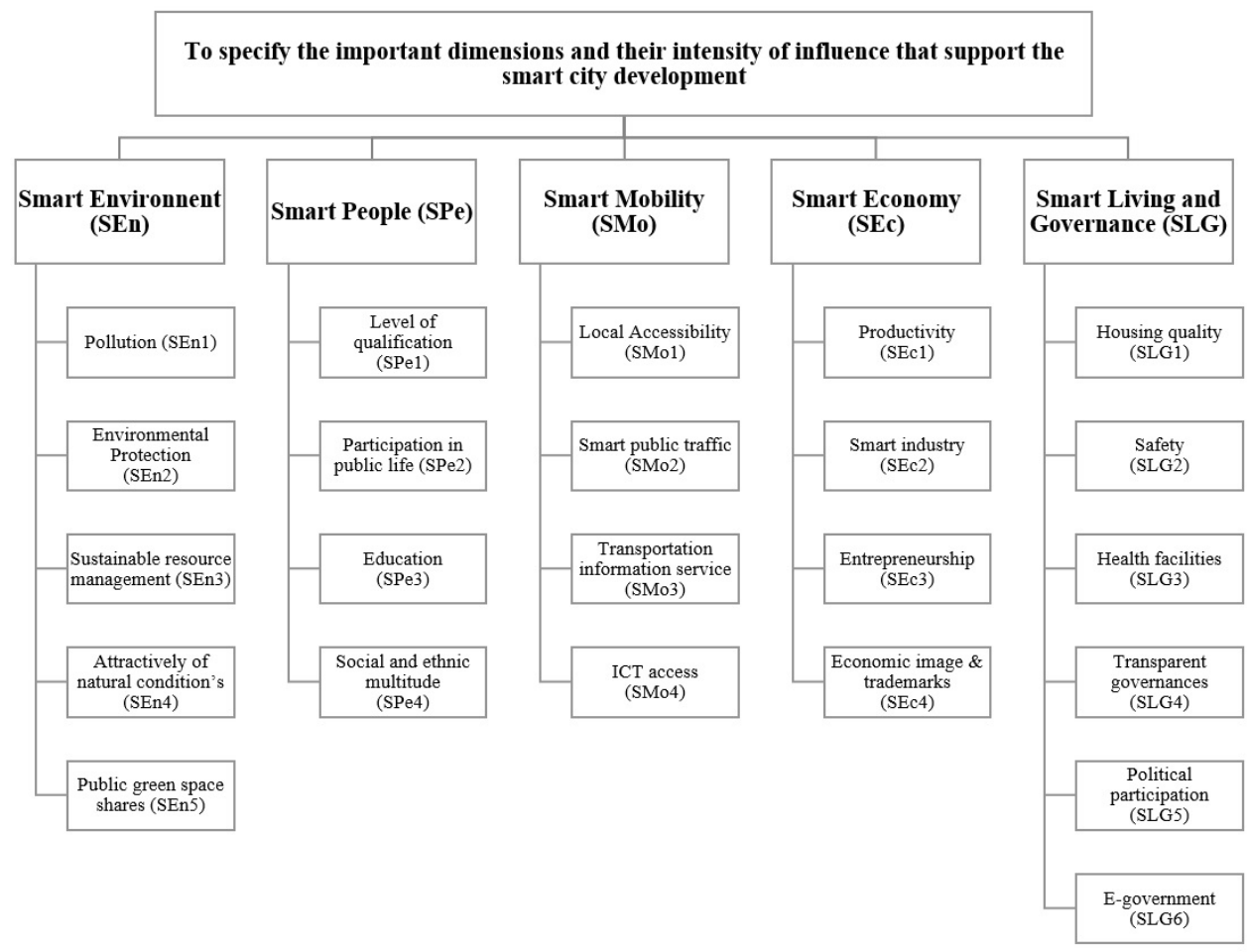

Figure 2. Hierarchical structure of dimension/criteria for SCD. 
Table 5. The principal dimensions/criteria reported in literature.

\begin{tabular}{|c|c|c|}
\hline Dimensions & Criteria & References \\
\hline \multirow{5}{*}{ Smart Environment (SEn) } & Pollution (SEn1) & {$[3,9,18,19,27,83-86]$} \\
\hline & Environmental Protection (SEn2) & {$[12,19,27,72,82,86,87]$} \\
\hline & Sustainable resource management (SEn3) & {$[12,19,27,39,72,88-90]$} \\
\hline & Attractively of natural condition's (SEn4) & {$[12,19,27,82,86,87]$} \\
\hline & Public green space shares (SEn5) & {$[19,85]$} \\
\hline \multirow{4}{*}{ Smart People (SPe) } & Level of qualification (SPe1) & [19] \\
\hline & Participation in public life (SPe2) & {$[19,38,39]$} \\
\hline & Education (SPe3) & {$[11,12,19,27,83,84,90]$} \\
\hline & Social and ethnic multitude (SPe4) & {$[19,27,39,40]$} \\
\hline \multirow{4}{*}{ Smart Mobility (Transportation and ICT) (SMo) } & Local Accessibility (SMo1) & [19] \\
\hline & Smart public traffic (SMo2) & {$[12,72,83,84,91]$} \\
\hline & Transportation information service (SMo3) & {$[12,19,27,72,83,84]$} \\
\hline & ICT access (SMo4) & {$[3,12,18,19,27,92]$} \\
\hline \multirow{4}{*}{ Smart Economy (SEc) } & Productivity (SEc1) & {$[19,27]$} \\
\hline & Smart industry (SEc2) & {$[27,72]$} \\
\hline & Entrepreneurship (SEc3) & {$[19,27,93]$} \\
\hline & Economic image \& trademarks (SEc4) & {$[19,27,40]$} \\
\hline \multirow{6}{*}{ Smart Living and Governance (SLG) } & Housing quality (SLG1) & {$[12,19,72,89,90]$} \\
\hline & Safety (SLG2) & {$[12,18,72,94,95]$} \\
\hline & Health facilities (SLG3) & {$[12,19,22,24,27,72]$} \\
\hline & Transparent governances (SLG4) & {$[12,19,23,27,90,96]$} \\
\hline & Political participation (SLG5) & {$[19,27,40]$} \\
\hline & E-government (SLG6) & {$[3,27,72]$} \\
\hline
\end{tabular}

Stage II: Computing the relative importance of identified dimensions/criteria by IF-AHP. The intuitionistic Fuzzy AHP method is utilized to prioritize the selected dimensions/criteria concerning their importance. For that, a structural hierarchy is utilized to evaluate the problem. It is composed of 3 levels: a goal statement (Level I), the principal dimensions (Level II), and criteria (Level III), as presented in Figure 2.

Initially, the weight of each expert's input is computed based on linguistic expressions given in Table 4. The weights are calculated by using Equation (16) and the calculated weights are shown in Table 6. From each expert, a pairwise comparison evaluation matrix of the principal dimensions and each criterion is constructed according to Saaty's scale considering intuitionistic fuzzy numbers given in Table 3. Table A1 (see Appendix A) presents the pairwise comparison evaluation matrix of the principal dimensions used in this study, while Figure 3 presents the relative importance weights for the principal dimensions and similarly for all criteria. In addition, the global weights of all criteria shown in Figure 4 are calculated by multiplying the relative importance weights of criteria by their corresponding principal dimensions importance weights.

Table 6. Importance of experts inputs.

\begin{tabular}{ccccc}
\hline Experts & $\mu$ & $\mathbf{v}$ & $\pi$ & $\lambda_{\boldsymbol{k}}$ \\
\hline E1 & 0,75 & 0,2 & 0,05 & 0,146899 \\
E2 & 0,9 & 0,05 & 0,05 & 0,176279 \\
E3 & 0,5 & 0,4 & 0,1 & 0,103373 \\
E4 & 0,75 & 0,2 & 0,05 & 0,146899 \\
\hline
\end{tabular}


Stage III: Specifying interdependence between the selected dimensions/criteria by IF-DEMATEL. The questionnaires completed by experts contain experts' judgment. Each expert's judgment is obtained by a direct relation matrix that shows the evaluation of interrelationship between elements using a linguistic rating scale. It shows the interrelationship and influence of principal dimensions. The completed direct relation matrix for principal dimensions by the experts is presented in Table A2 (see Appendix A). The averages of judgments are computed using Equation (8) where $k^{i j}$ is the corresponding value of the intuitionistic fuzzy number of $k$ expert's judgment when comparing $i$ to $j$. Furthermore, the normalized initial direct relation matrix is calculated by using Equations (9) and (10). The total relation matrix is computed by using Equation (11) and is presented in Table 7.

Table 7. Total relation matrix

\begin{tabular}{cccccc}
\hline Principal Dimensions & SEn & SPe & SMo & SEc & SLG \\
\hline SEn & 0 & 0,219909 & 0,523478 & 0,170699 & 0,091448 \\
SPe & 0,228143 & 0 & 0,560997 & 0,182934 & 0,209655 \\
SMo & 0,523401 & 0,393716 & 0 & 0,193498 & 0,220064 \\
SEc & 0,077271 & 0,084476 & 0,088535 & 0 & 0,364392 \\
SLG & 0,211093 & 0,491708 & 0,243873 & 0,079524 & 0 \\
\hline
\end{tabular}

The $(D+R)$ and $(D-R)$ values are calculated using Equations (12) and (14) as shown in Table 8 . The addition of rows and columns of the total relation matrix makes vectors $D$ and $R$, respectively. A dimension is considered as a member of the cause division if $(D-R)$ is positive, and in the case of its negative value, the dimension is attributed to the effect division. $(D+R)$ that is the horizontal axis vector named 'prominence' presents the importance of a dimension. Therefore, the causal diagram is represented by mapping the data set of the $(D+R$ and $D-R)$ as shown in Figure 5 .

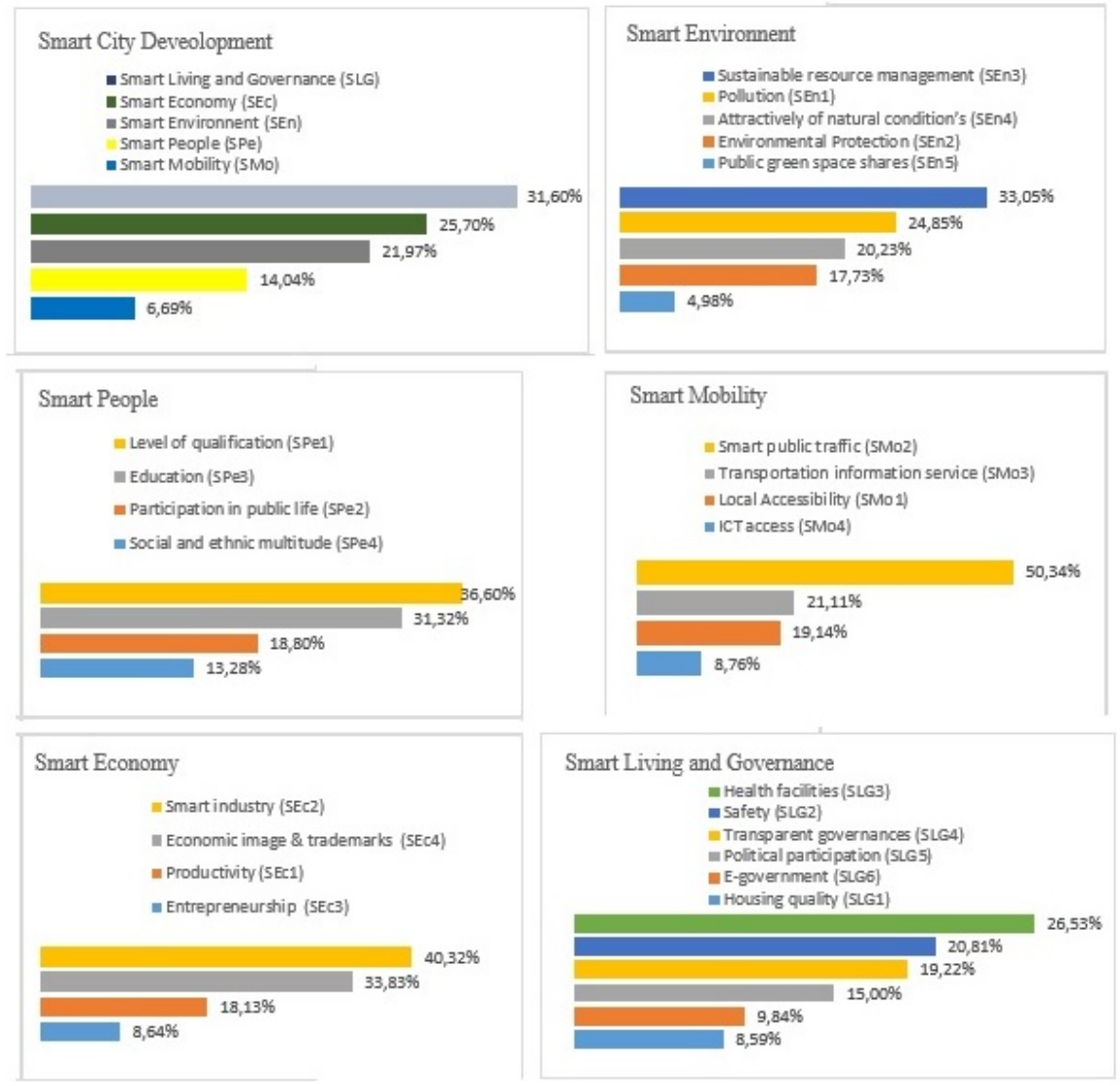

Figure 3. The weight values (\%) of the smart city dimensions. 


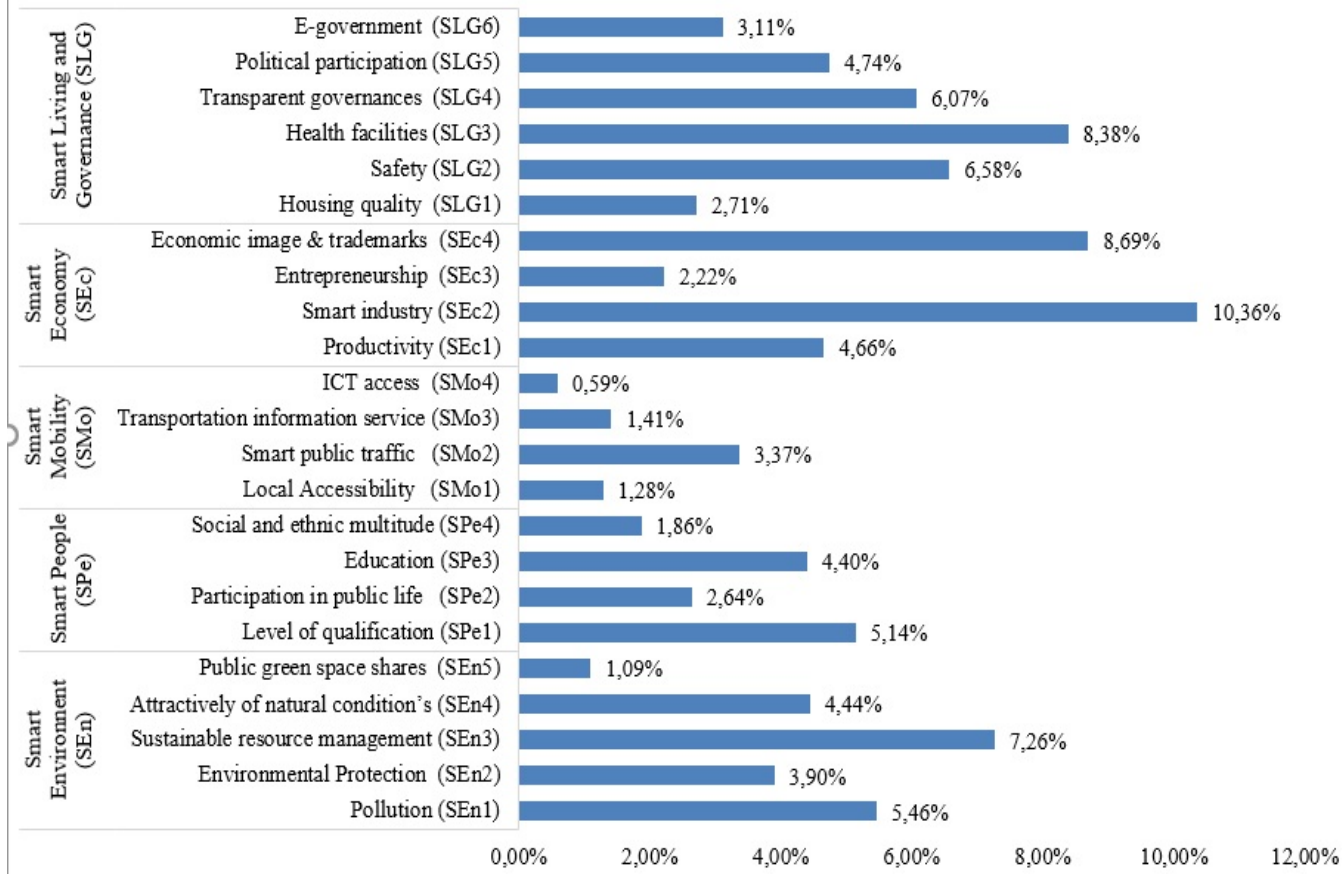

Figure 4. The weight values (\%) of smart city criteria.

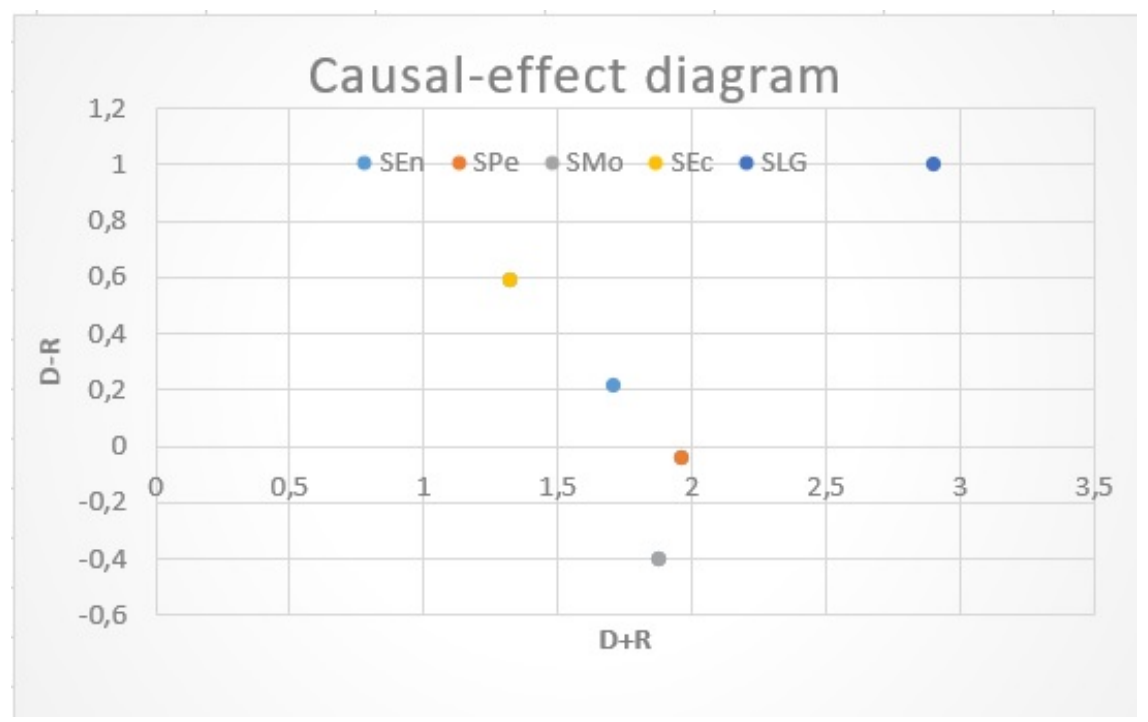

Figure 5. The causal-effect diagram for various dimensions.

\section{Results and Discussions}

The outcomes of the suggested framework's application are shown in this section. The consequences and managerial insights of these findings are also discussed.

\subsection{IF-AHP Results}

The goal of the IFAHP procedure is to compute the priorities of dimensions/criteria that affect SCD and assist policymakers in devising flexible short-term decision-making measures by considering the imprecision and ambiguity of the problem's inherent linguistic nature. The global importance weights of the main dimensions and criteria are shown in Figures 3 and 4.

A total of 23 most criteria impacting SCD as suggested by the experts are included in the initial stage of this study. These criteria are organized under five different dimensions and IF-AHP and IF-DEMATEL are used to explore the influence intensity of these criteria on SCD projects. Results show that SLG obtains the highest weight because it holds the 
prime range $(0,3160)$ as shown in Figure 3 , followed by SEc $(0,2570)$, SEn $(0,2197)$, SPe $(0,1404)$, and SMo $(0,0669)$. This explains that the experts give higher attention to the effects of SLG dimension. Also, the results are consistent with [97] which considers the criteria associated to SLG as crucial for the development of smart cities. Similarly, Ozkaya et al. point out the significance of SEc as the key criteria with respect to SCD [27].

Among the criteria in each dimension, the development of the smart industry $(0,1036)$, economic image \& trademarks $(0,0896)$, health facilities $(0,0838)$, and sustainable resource management $(0,0726)$ are more important and influencing for SCD as presented in Figure 4. The safety system $(0,0658)$, transparent governance $(0,0607)$, and pollution $(0,0546)$ also act as essential criteria with respect to the geographical, living and governance, and environmental system of the city. Among the mobility criteria, smart public traffic $(0,0337)$, transportation information service $(0,0141)$, and local accessibility $(0,0128)$ are the most important criteria that influence the development of intelligent transportation. These results are following Albino et al. (2015) which points out that the transportation system is critical due to its high importance in SCD [98].

Table 8. The results and relation vectors.

\begin{tabular}{ccccccc}
\hline & $\mathbf{R}$ & $\mathbf{D}$ & $\mathbf{D}+\mathbf{R}$ & Rank (D + R) & $\mathbf{D}-\mathbf{R}$ & Rank (D - R) \\
\hline SEn & 0,743388 & 0,962636 & 1,706024 & 4 & 0,219249 & 3 \\
\hline SPe & 0,998796 & 0,962636 & 1,961432 & 2 & $-0,03616$ & 4 \\
\hline SMo & 1,137181 & 0,734493 & 1,871674 & 3 & $-0,40269$ & 5 \\
\hline SEc & 0,364392 & 0,95448 & 1,318872 & 5 & 0,590088 & 2 \\
\hline SLG & 0,946673 & 1,953276 & 2,89995 & 1 & 1,006603 & 1 \\
\hline
\end{tabular}

\subsection{IF-DEMATEL Results}

Because the IF-AHP technique only calculates the weights of dimensions/criteria impacting the SCD, the IF-DEMATEL approach can be used to track the degree of influence and relationship between the selected dimensions/criteria. Results from IF-DEMATEL reveal (presented in Table 8 and Figure 5) that smart mobility (SMo) and smart people (SPe) are placed into the effect set that is easily influenced by other dimensions, as their $(D-R)$ values are negative, indicating that their influential impact $(D)$ is lower than their influenced impact $(R)$. The cause set, on the other hand, includes smart living and governance (SLG), smart environment (SEn), and smart economy (SEc), all of which have an impact on the SCD, so they deserve more attention. The elements of the cause set have a higher influential impact $(D)$ than the influenced impact $(R)$.

The $(D+R)$ score represents a dimension's relative importance. With the highest $(D+R)$ value, smart living and governance (SLG) (the value is equal to 2,89995) should be considered a rather important dimension for SCD. In the $(D+R)$ ranking, smart people (SPe), smart mobility (SMo), and smart environment (SEn) are ranked after smart living and governance (SGL). SLG also has the highest position in the $(D-R)$ rating, followed by the smart economy (SEc) and environment (SEn), respectively. Generally, we must consider both $(D+R)$ and $(D-R)$ ranking, and as shown in Figure 5, the SLG has an important influence on the other dimensions. In the context of Morocco, the SLG main dimension proves to be crucial in the development of the smart city. Despite this, SMo's $D-R$ score is $-0,40269$, the smallest score among effect dimensions, indicating that it is clearly influenced by other dimensions. By evaluating both cause and effect sets, we are able to find the three most essential dimensions. SLG is shown to be the most important dimension, followed by SEc and SEn.

\subsection{Managerial Implications}

The findings of this study have significant managerial consequences. The results of the analysis propose various managerial recommendations that are discussed as follows: 
- Identifying various dimensions/criteria that affect SCD in developing countries. From the SCD perspective, the present research reveals five main dimensions and twenty-three criteria from existing literature. The current study is an attempt to identify several common dimensions/criteria related to SCD for developing countries. According to the literature and expert discussions, there are five major dimensions: $\mathrm{SEc}$, SEn, SLG, SMo, and SPe. All these dimensions are strategic for enhancing the evaluation of SCD.

- Proposing a robust framework for smart city development evaluation for developing countries. The policymakers are often facing several issues related to urbanization. This study presents a robust framework for smart city development evaluation for developing countries. Combined IF-AHP and IF-DEMATEL techniques have been used for evaluating dimensions/criteria affecting SCD. IF-AHP is a consistent method to compute the priorities and relative ranks of each dimension and criterion. Moreover, the IF-DEMATEL technique is used to specify the effect and cause sets among selected dimensions/criteria. The policymakers can benefit from this framework by identifying the significant dimensions/criteria for analyzing and understanding the most critical factors related to SCD and work on these factors to make Morocco's smart city initiatives sustainable. Furthermore, policymakers should be aware that the study's findings may vary based on the case study. Policymakers will notice that the proposed methodology can consider the ambiguity, but the findings of this case situation may not be generalizable.

\section{Conclusions, Limitations and Future Work}

This study primarily focuses on exploring the most important dimensions/criteria affecting smart city development projects with respect to developing countries, especially the Moroccan context. For this purpose, a novel framework is proposed that utilizes the IF-AHP and IF-DEMATEL techniques. Initially, important criteria are extracted from a comprehensive analysis of the literature and other documents on smart city development. Experts from different domains including environment, information technology, and construction engineering, etc., are asked to provide their opinion on the importance, validity, and interrelationships between the selected criteria. Later, IF-AHP is used to compute the weights of selected dimensions/criteria to perform a hierarchical structure. Finally, the IF-DEMATEL method is employed to evaluate the driving force and dependence of each dimension/criterion which has an impact on smart city development. The proposed framework illustrates that the consideration of smart living and governance, smart economy, and smart environment are the basis for the successful implementation of smart city projects.

Analysis suggests that the acquired IF-AHP results are frequently used to build shortterm decision-making strategies by defining the importance/priorities of the identified dimensions/criteria affecting smart city development. By assessing the complicated interrelationships among the dimensions/criteria and classifying them as cause and effect sets, the IF-DEMATEL outcomes can improve the decision-making effects for a longer duration. The proposed approach in this study presents findings that conform to previous studies, as well as, preference dimensions and fields to enhance the performance of cities, especially in developing countries. Consequently, the prime objective of this study is to support policymakers in determining the fields that require enhancements to maintain sustainability and compare the present status with competitors.

\subsection{Implications of the study}

The current study has powerful implications for researchers and practitioners, as presented below:

- The literature review distinctly shows that the smart city projects have a direct impact on a country's economy. Many emerging economies, including Indonesia, China, India, and the United Arab Emirates (UAE), etc., are launching smart city initiatives because of their direct positive benefits to the economy and the citizens. This study 
presents a comprehensive list of 23 important dimensions/criteria that influences the effective implementation of smart city development projects in developing nations like Morocco.

- The combined IF-AHP and IF-DEMATEL methodology used in the current study holds several advantages and potentials for both researchers and practitioners. The use of IF-AHP aids in evaluating the weights of dimensions/criteria derived from literature review and expert opinions. Similarly, the use of IF-DEMATEL provides the positioning of different levels and interrelations among dimensions. Using IF-AHP and IF-DEMATEL a structural framework is devised for evaluating the influential dimensions/criteria for smart city development with respect to developing countries like Morocco which can assist practitioners in analyzing the relationship between criteria and understanding the usage of specific dimensions/criteria at different levels.

- The smart city framework proposed in the current work covers a wide range of sustainability and environmental aspects that affect smart cities. The successful implementation of the created framework can help in improving society's welfare and laying out a roadmap for community development through smart city development. Furthermore, the adoption of the smart city will assist in providing its inhabitants with a high-quality living.

\subsection{Limitations and Future Works}

Despite the above-discussed contributions and advantages, the present work is not without its limitations. Firstly, the data collected in this study through a questionnaire is from a limited number of experts, and the capability and experience of experts vary, which may affect the results. For future research, data from a large number of experts can be collected and results can be compared to the present study. Moreover, the hybrid IF AHP- IF DEMATEL approach relies on the judgments of experts only. For future work, the analysis and evaluation can be done by using other MCDM methods like ANP, Preference Vector Method, Interpretive Structural Modelling, and PPROMTHEE to improve the application experience. Recently, neutrosophic sets, as a novel extension of fuzzy sets, are proposed by Smarandache [49], which is a powerful tool for modeling ambiguity and vagueness. As a result, assessing dimensions/criteria under neutrosophic fuzzy environments could also be addressed in the future. The proposed framework emphasizes smart city development for developing countries like Morocco, but this proposal can also be adopted for other developing countries. Similarly, experts from other related domains may be added in the process to widen the scope of the study.

Author Contributions: Conceptualization, M.H. and O.B.; Data curation, F.E.B. and M.L.; Formal analysis, O.B. and I.A.; Investigation, M.H., F.E.B. and M.L.; Methodology, N.A. and F.R.; Project administration, F.R.; Resources, F.E.B. and N.A.; Software, M.L. and F.R.; Supervision, I.A.; Visualization, O.B.; Writing—original draft, M.H.; Writing—review \& editing, I.A. All authors have read and agreed to the published version of the manuscript.

Funding: This research was supported by Basic Science Research Program through the National Research Foundation of Korea(NRF) funded by the Ministry of Education(NRF-2021R1A6A1A03039493).

Institutional Review Board Statement: Not applicable.

Informed Consent Statement: Not applicable.

Data Availability Statement: Not applicable.

Conflicts of Interest: The authors declare that there is no conflict of interest. 


\section{Appendix A}

Table A1. The Experts judgments for the principal dimensions using linguistic variables.

\begin{tabular}{|c|c|c|c|c|c|c|}
\hline Fxports & Dimensions & & & & & \\
\hline 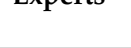 & & SEn & SPe & SMo & SEc & SLG \\
\hline \multirow{5}{*}{ Expert 1} & SEn & M & $\mathrm{VH}$ & $\mathrm{H}$ & $\mathrm{MH}$ & $\mathrm{M}$ \\
\hline & $\mathrm{SPe}$ & & $\mathrm{M}$ & $\mathrm{L}$ & $\mathrm{H}$ & $\mathrm{VH}$ \\
\hline & SMo & & & $\mathrm{M}$ & $\mathrm{H}$ & $\mathrm{EH}$ \\
\hline & SEc & & & & M & $\mathrm{VH}$ \\
\hline & SLG & & & & & M \\
\hline \multirow{5}{*}{ Expert 2} & SEn & $\mathrm{M}$ & ML & $\mathrm{MH}$ & $\mathrm{EH}$ & $\mathrm{VH}$ \\
\hline & $\mathrm{SPe}$ & & M & $\mathrm{EH}$ & ML & $\mathrm{L}$ \\
\hline & SMo & & & $\mathrm{M}$ & $\mathrm{MH}$ & $\mathrm{MH}$ \\
\hline & SEc & & & & M & M \\
\hline & SLG & & & & & M \\
\hline \multirow{5}{*}{ Expert 3} & SEn & $\mathrm{M}$ & VL & $\mathrm{L}$ & $\mathrm{VH}$ & $\mathrm{H}$ \\
\hline & $\mathrm{SPe}$ & & M & ML & MH & $\mathrm{EH}$ \\
\hline & SMo & & & $\mathrm{M}$ & $\mathrm{H}$ & $\mathrm{VH}$ \\
\hline & SEc & & & & M & $\mathrm{EH}$ \\
\hline & SLG & & & & & $\mathrm{M}$ \\
\hline \multirow{5}{*}{ Expert 4} & SEn & $\mathrm{M}$ & $\mathrm{VH}$ & $\mathrm{H}$ & $\mathrm{MH}$ & $\mathrm{M}$ \\
\hline & SPe & & $\mathrm{M}$ & $\mathrm{L}$ & $\mathrm{H}$ & $\mathrm{VH}$ \\
\hline & SMo & & & $\mathrm{M}$ & $\mathrm{H}$ & $\mathrm{EH}$ \\
\hline & SEc & & & & $\mathrm{M}$ & $\mathrm{VH}$ \\
\hline & SLG & & & & & $M$ \\
\hline
\end{tabular}

Table A2. The judgments of experts for the principal dimensions by using linguistic expressions.

\begin{tabular}{ccccccc}
\hline \multirow{2}{*}{ Experts } & Dimensions & & & & & \\
\cline { 2 - 7 } & & SEn & SPe & SMo & SEc & SLG \\
\cline { 2 - 7 } Expert 1 & SEn & ALI & FLI & FHI & FLI & LI \\
\cline { 2 - 7 } & SPe & FLI & ALI & FHI & FLI & FLI \\
\cline { 2 - 7 } & SMo & FHI & MI & ALI & FLI & FLI \\
\cline { 2 - 7 } & SEc & LI & LI & LI & ALI & FHI \\
\cline { 2 - 7 } & SLG & FLI & FHI & FLI & LI & ALI \\
\cline { 2 - 7 } & SEn & ALI & MI & MI & MI & ALI \\
\cline { 2 - 7 } & SPe & LI & ALI & FHI & LI & MI \\
\cline { 2 - 7 } & SMo & FHI & FHI & ALI & LI & MI \\
\cline { 2 - 7 } & SLG & LI & LI & ALI & ALI & FHI \\
\cline { 2 - 7 } Expert 3 & SEn & ALI & LI & FHI & LI & FLI \\
\cline { 2 - 6 } & SPe & MI & ALI & MI & MI & LI \\
\cline { 2 - 6 } & SEo & MI & FLI & ALI & MI & LI \\
\cline { 2 - 6 } & SEG & LI & LI & FLI & ALI & MI \\
\cline { 2 - 6 } & SLG & MI & MI & MI & FLI & ALI \\
\hline
\end{tabular}


Table A2. Cont.

\begin{tabular}{|c|c|c|c|c|c|c|}
\hline \multirow{2}{*}{ Experts } & \multicolumn{6}{|l|}{ Dimensions } \\
\hline & & SEn & $\mathrm{SPe}$ & SMo & SEc & SLG \\
\hline \multirow{5}{*}{ Expert 4} & SEn & ALI & FLI & FHI & FLI & LI \\
\hline & $\mathrm{SPe}$ & FLI & ALI & FHI & FLI & FLI \\
\hline & SMo & FHI & MI & ALI & FLI & FLI \\
\hline & SEc & $\mathrm{LI}$ & LI & LI & ALI & FHI \\
\hline & SLG & FLI & FHI & FLI & LI & ALI \\
\hline
\end{tabular}

\section{References}

1. The World Bank. World Population 2020. Available online: https://data.worldbank.org/indicator/SP.POP.TOTL?end=2020\&start= 1960\&view $=$ chart (accessed on 10 September 2021).

2. Gaur, A.; Scotney, B.; Parr, G.; McClean, S. Smart City Architecture and its Applications Based on IoT. Procedia Comput. Sci. 2015, 52, 1089-1094. [CrossRef]

3. Bakıc1, T.; Almirall, E.; Wareham, J. A smart city initiative: The case of Barcelona. J. Knowl. Econ. 2013, 4, 135-148. [CrossRef]

4. Abellá-García, A.; de Urbina-Criado, M.O.; De-Pablos-Heredero, C. The Ecosystem of Services Around Smart Cities: An Exploratory Analysis. Procedia Comput. Sci. 2015, 64, 1075-1080. [CrossRef]

5. Belanche, D.; Casaló, L.V.; Orús, C. City attachment and use of urban services: Benefits for smart cities. Cities 2016, 50, 75-81. [CrossRef]

6. Bibri, S.E.; Krogstie, J. Smart sustainable cities of the future: An extensive interdisciplinary literature review. Sustain. Cities Soc. 2017, 31, 183-212. [CrossRef]

7. Lee, M.; Uhm, Y.; Hwang, Z.; Kim, Y.; Jo, J.; Park, S. An Urban Computing Framework for Autonomous Services in a U-City. In Proceedings of the 2007 International Conference on Convergence Information Technology (ICCIT 2007), Gwangju, Korea, 21-23 November 2007. [CrossRef]

8. Jain, B.; Brar, G.; Malhotra, J.; Rani, S. A novel approach for smart cities in convergence to wireless sensor networks. Sustain. Cities Soc. 2017, 35, 440-448. [CrossRef]

9. Khan, Z.A. Using energy-efficient trust management to protect IoT networks for smart cities. Sustain. Cities Soc. 2018, 40, 1-15. [CrossRef]

10. Paroutis, S.; Bennett, M.; Heracleous, L. A strategic view on smart city technology: The case of IBM Smarter Cities during a recession. Technol. Forecast. Soc. Chang. 2014, 89, 262-272. [CrossRef]

11. Liu, Y.; Wang, H.; Tzeng, G.H. From Measure to Guidance: Galactic Model and Sustainable Development Planning toward the Best Smart City. J. Urban Plan. Dev. 2018, 144, 04018035. [CrossRef]

12. Yadav, G.; Mangla, S.K.; Luthra, S.; Rai, D.P. Developing a sustainable smart city framework for developing economies: An Indian context. Sustain. Cities Soc. 2019, 47, 101462. [CrossRef]

13. Wu, Y.J.; Chen, J.C. A structured method for smart city project selection. Int. J. Inf. Manag. 2021, 56, 101981. [CrossRef]

14. Lee, S.K.; Kwon, H.R.; Cho, H.; Kim, J.; Lee, D. International Case Studies of Smart Cities; Inter-American Bank: Pangyo, Korea, 2016.

15. Angelidou, M. Smart cities: A conjuncture of four forces. Cities 2015, 47, 95-106. [CrossRef]

16. Martin, C.J.; Evans, J.; Karvonen, A. Smart and sustainable? Five tensions in the visions and practices of the smart-sustainable city in Europe and North America. Technol. Forecast. Soc. Chang. 2018, 133, 269-278. [CrossRef]

17. De Jong, M.; Joss, S.; Schraven, D.; Zhan, C.; Weijnen, M. Sustainable-smart-resilient-low carbon-eco-knowledge cities; making sense of a multitude of concepts promoting sustainable urbanization. J. Clean. Prod. 2015, 109, 25-38. [CrossRef]

18. Hollands, R.G. Will the real smart city please stand up? City 2008, 12, 303-320. [CrossRef]

19. Lazaroiu, G.C.; Roscia, M. Definition methodology for the smart cities model. Energy 2012, 47, 326-332. [CrossRef]

20. Adapa, S. Indian smart cities and cleaner production initiatives-Integrated framework and recommendations. J. Clean. Prod. 2018, 172, 3351-3366. [CrossRef]

21. Ibrahim, M.; El-Zaart, A.; Adams, C. Smart sustainable cities roadmap: Readiness for transformation towards urban sustainability. Sustain. Cities Soc. 2018, 37, 530-540. [CrossRef]

22. Aina, Y.A. Achieving smart sustainable cities with GeoICT support: The Saudi evolving smart cities. Cities 2017, 71, 49-58. [CrossRef]

23. Niaros, V.; Kostakis, V.; Drechsler, W. Making (in) the smart city: The emergence of makerspaces. Telemat. Inform. 2017, 34, 1143-1152. [CrossRef]

24. Sta, H.B. Quality and the efficiency of data in "Smart-Cities". Future Gener. Comput. Syst. 2017, 74, 409-416. [CrossRef]

25. Yigitcanlar, T.; Kamruzzaman, M. Does smart city policy lead to sustainability of cities? Land Use Policy 2018, 73, 49-58. [CrossRef]

26. Committee of E-Madina. Smart City Mission and Objectives. Available online: https://www.e-madina.org/presentation/missionet-objectifs (accessed on 2 January 2021). 
27. Ozkaya, G.; Erdin, C. Evaluation of smart and sustainable cities through a hybrid MCDM approach based on ANP and TOPSIS technique. Heliyon 2020, 6, e05052. [CrossRef]

28. Rad, T.G.; Sadeghi-Niaraki, A.; Abbasi, A.; Choi, S.M. A methodological framework for assessment of ubiquitous cities using ANP and DEMATEL methods. Sustain. Cities Soc. 2018, 37, 608-618.

29. Zolfani, S.H.; Pourhossein, M.; Yazdani, M.; Zavadskas, E.K. Evaluating construction projects of hotels based on environmental sustainability with MCDM framework. Alex. Eng. J. 2018, 57, 357-365. [CrossRef]

30. Katal, F.; Fazelpour, F. Multi-criteria evaluation and priority analysis of different types of existing power plants in Iran: An optimized energy planning system. Renew. Energy 2018, 120, 163-177. [CrossRef]

31. Si, J.; Marjanovic-Halburd, L.; Nasiri, F.; Bell, S. Assessment of building-integrated green technologies: A review and case study on applications of Multi-Criteria Decision Making (MCDM) method. Sustain. Cities Soc. 2016, 27, 106-115. [CrossRef]

32. Mattoni, B.; Pompei, L.; Losilla, J.; Bisegna, F. Planning smart cities: Comparison of two quantitative multicriteria methods applied to real case studies. Sustain. Cities Soc. 2020, 60, 102249. [CrossRef]

33. Ahuja, K.; Khosla, A. Network selection criterion for ubiquitous communication provisioning in smart cities for smart energy system. J. Netw. Comput. Appl. 2019, 127, 82-91. [CrossRef]

34. MARUF, M.; AYÇİN, E. Evaluation Of The Livability Levels Of Metropolitan Cities By Dematel-Based Analytic Network Process (Danp) And Mairca Methods. Int. J. Eurasia Soc. Sci. 2020, 11, 417-432.

35. Giffinger, R.; Fertner, C.; Kramar, H.; Meijers, E. City-ranking of European medium-sized cities. Cent. Reg. Sci. Vienna UT 2007, $1-12$.

36. Chourabi, H.; Nam, T.; Walker, S.; Gil-Garcia, J.R.; Mellouli, S.; Nahon, K.; Pardo, T.A.; Scholl, H.J. Understanding smart cities: An integrative framework. In Proceedings of the 2012 45th Hawaii International Conference on System Sciences, Maui, HI, USA, 4-7 January 2012; pp. 2289-2297.

37. Shapiro, J.M. Smart cities: Quality of life, productivity, and the growth effects of human capital. Rev. Econ. Stat. 2006, 88, 324-335. [CrossRef]

38. Eger, J.M. Smart growth, smart cities, and the crisis at the pump a worldwide phenomenon. I-WAYS J. E-Gov. Policy Regul. 2009, 32, 47-53. [CrossRef]

39. Thuzar, M. Urbanization in Southeast Asia: Developing smart cities for the future? In Regional Outlook; ISEAS Publishing: Singapore, 2011; pp. 96-100.

40. Barrionuevo, J.M.; Berrone, P.; Ricart, J.E. Smart cities, sustainable progress. IESE Insight 2012, 14, 50-57. [CrossRef]

41. Cisco Smart City. Available online: http://www.cisco.com/web/learning/le21/le34/downloads/689/nobel/2005/docs (accessed on 10 March 2021).

42. Siemens Smart City. Available online: http://www.siemens.com/innovation/en/home/pictures-of-the-future.html (accessed on 12 March 2021).

43. Canada Smart City. Available online: https://smartcitiescouncil.com/events/smart-city-expo-montreal (accessed on 12 June 2021$)$.

44. Batlle-Montserrat, J.; Blat, J.; Abadal, E. Local e-government benchlearning: Impact analysis and applicability to smart cities benchmarking. Inf. Polity 2016, 21, 43-59. [CrossRef]

45. Choe, G.H. Basic probability theory. In Stochastic Analysis for Finance with Simulations; Springer: Berlin/Heidelberg, Germany, 2016; pp. 41-74.

46. Giang, P.H. Subjective foundation of possibility theory: Anscombe-Aumann approach. Inf. Sci. 2016, 370, 368-384. [CrossRef]

47. Berger, H.H.; Wiedmann, S.K. Merged-transistor logic (MTL)-A low-cost bipolar logic concept. IEEE J. Solid-State Circuits 1972, 7, 340-346. [CrossRef]

48. Pawlak, Z. Rough sets. Int. J. Comput. Inf. Sci. 1982, 11, 341-356. [CrossRef]

49. Pramanik, S.; Mondal, K. Cotangent similarity measure of rough neutrosophic sets and its application to medical diagnosis. J. New Theory 2015, 4, 90-102.

50. Zelentsov, L.; Mailyan, L. Creation of intelligent management systems in construction. MATEC Web Conf. 2017, $106,08051$. [CrossRef]

51. de Alencar Bezerra, S.; dos Santos, F.J.; Pinheiro, P.R.; Barbosa, F.R. Dynamic Evaluation of the Energy Efficiency of Environments in Brazilian University Classrooms Using DEA. Sustainability 2017, 9, 2373. [CrossRef]

52. Moghadam, S.T.; Toniolo, J.; Mutani, G.; Lombardi, P. A GIS-statistical approach for assessing built environment energy use at urban scale. Sustain. Cities Soc. 2018, 37, 70-84. [CrossRef]

53. Agugiaro, G. ENABLING “ENERGY-AWARENESS” IN THE SEMANTIC 3D CITY MODEL OF VIENNA. ISPRS Ann. Photogramm. Remote Sens. Spat. Inf. Sci. 2016, 4. [CrossRef]

54. Bhattacharya, D.; Painho, M. Smart cities intelligence system (smacisys) integrating sensor web with spatial data infrastructures (sensdi). ISPRS Ann. Photogramm. Remote. Sens. Spat. Inf. Sci. 2017, 4, 21-28. [CrossRef]

55. Terribile, F.; Agrillo, A.; Bonfante, A.; Buscemi, G.; Colandrea, M.; D’Antonio, A.; De Mascellis, R.; De Michele, C.; Langella, G.; Manna, P.; et al. A Web-based spatial decision supporting system for land management and soil conservation. Solid Earth 2015, 6, 903-928. [CrossRef]

56. Wang, E.; Attard, S.; Everingham, Y.; Philippa, B.; Xiang, W. Smarter irrigation management in the sugarcane farming system using Internet of Things. In Proceedings of the 2018 Conference of the Australian Society of Sugar Cane Technologists, Mackay, QLD, Australia, 18-20 April 2018; pp. 117-122. 
57. Khansari, N.; Silverman, B.G.; Du, Q.; Waldt, J.B.; Braham, W.W.; Lee, J.M. An agent-based decision tool to explore urban climate \& smart city possibilities. In Proceedings of the 2017 Annual IEEE International Systems Conference (SysCon), Montreal, QC, Canada, 24-27 April 2017. [CrossRef]

58. Hanine, M.; Boutkhoum, O.; Tikniouine, A.; Agouti, T. Application of an integrated multi-criteria decision making AHP-TOPSIS methodology for ETL software selection. SpringerPlus 2016, 5, 1-17. [CrossRef]

59. Balsara, S.; Jain, P.K.; Ramesh, A. An integrated approach using AHP and DEMATEL for evaluating climate change mitigation strategies of the Indian cement manufacturing industry. Environ. Pollut. 2019, 252, 863-878. [CrossRef]

60. Mohsen Karrabi, M.G.; Mohammadi, A.; Dadvar, A. Controlling air pollution in a city: A perspective from SOAR-PESTLE analysis. Integr. Environ. Assess. Manag. 2018, 14, 480-488. [CrossRef]

61. Rondini, A.; Lagorio, A.; Pinto, R.; Pezzotta, G. A multi-criteria decision making approach for prioritising product-service systems implementation in smart cities. Int. J. Manag. Decis. Mak. 2018, 17, 415. [CrossRef]

62. Saaty, T.; Paola, P.D. Rethinking Design and Urban Planning for the Cities of the Future. Buildings 2017, 7, 76. [CrossRef]

63. Mokoena, B.T.; Musakwa, W.; Moyo, T. Developing the Well-Located Land Index to Establish Smart Human Settlements for the Ekurhuleni Municipality, South Africa. In Lecture Notes in Geoinformation and Cartography; Springer International Publishing: Berlin/Heidelberg, Germany, 2017; pp. 95-112. [CrossRef]

64. Mosannenzadeh, F.; Nucci, M.R.D.; Vettorato, D. Identifying and prioritizing barriers to implementation of smart energy city projects in Europe: An empirical approach. Energy Policy 2017, 105, 191-201. [CrossRef]

65. Wang, Q.; Dai, H.N.; Wang, H. A Smart MCDM Framework to Evaluate the Impact of Air Pollution on City Sustainability: A Case Study from China. Sustainability 2017, 9, 911. [CrossRef]

66. Wey, W. Smart growth principles combined with fuzzy AHP and DEA approach to the transit-oriented development (TOD) planning in urban transportation systems. J. Energy Technol. Policy 2013, 3, 251-258.

67. Zadeh, L.A. Information and control. Fuzzy Sets 1965, 8, 338-353.

68. Atanassov, K. Intuitionistic fuzzy sets. Fuzzy Sets and Systems. 1986, 20, 87-96. [CrossRef]

69. Nehi, H.M.; Maleki, H.R. Intuitionistic fuzzy numbers and it's applications in fuzzy optimization problem. In Proceedings of the 9th WSEAS International Conference on Systems, Athens, Greece, 11-13 July 2005; pp. 1-5.

70. Ye, J. Expected value method for intuitionistic trapezoidal fuzzy multicriteria decision-making problems. Expert Syst. Appl. 2011, 38, 11730-11734. [CrossRef]

71. Bansal, A.; Kumar, P.; Issar, S. Evaluation of a 3PL company: An approach of fuzzy modelling. Int. J. Adv. Oper. Manag. 2014, 6, 131-161. [CrossRef]

72. Liu, H.W.; Wang, G.J. Multi-criteria decision-making methods based on intuitionistic fuzzy sets. Eur. J. Oper. Res. 2007, 179, 220-233. [CrossRef]

73. $\mathrm{Xu}, \mathrm{Z}$.; Liao, H. A survey of approaches to decision making with intuitionistic fuzzy preference relations. Knowl.-Based Syst. 2015, 80, 131-142. [CrossRef]

74. Gan, J.; Luo, L. Using DEMATEL and intuitionistic fuzzy sets to identify critical factors influencing the recycling rate of end-of-life vehicles in China. Sustainability 2017, 9, 1873. [CrossRef]

75. Govindan, K.; Khodaverdi, R.; Vafadarnikjoo, A. Intuitionistic fuzzy based DEMATEL method for developing green practices and performances in a green supply chain. Expert Syst. Appl. 2015, 42, 7207-7220. [CrossRef]

76. Nikjoo, A.V.; Saeedpoor, M. An intuitionistic fuzzy DEMATEL methodology for prioritising the components of SWOT matrix in the Iranian insurance industry. Int. J. Oper. Res. 2014, 20, 439-452. [CrossRef]

77. Fontela, E.; Gabus, A. The DEMATEL Observer, DEMATEL 1976 Report; Battelle Geneva Research Center: Geneva, Switzerland, 1976.

78. Saaty, T.L.; Shih, H.S. Structures in decision making: On the subjective geometry of hierarchies and networks. Eur. J. Oper. Res. 2009, 199, 867-872. [CrossRef]

79. Boran, F.E.; Genç, S.; Kurt, M.; Akay, D. A multi-criteria intuitionistic fuzzy group decision making for supplier selection with TOPSIS method. Expert Syst. Appl. 2009, 36, 11363-11368. [CrossRef]

80. EL HAJ, D.A. La ville marocaine et la nécessité d'une transformation à l'ère de la Smart City: Analyse des cas des villes de Tanger, Casablanca et Marrakech. Geopolit. Geostrategic Intell. 2020, 3, 66-84.

81. Apebi, L.L.B. Ville Intelligente au Maroc. 2015. Available online: http://www.e-madina.org/wp-content/uploads/2015/07/eMadina_le_Livre_Blanc_de_1APEBI_pour_les_villes_intelligentes_au_Maroc (accessed on 12 March 2021).

82. Han, H.; Hawken, S. Introduction: Innovation and identity in next-generation smart cities. City, Cult. Soc. 2018, 12, 1-4. [CrossRef]

83. Grossi, G.; Pianezzi, D. Smart cities: Utopia or neoliberal ideology? Cities 2017, 69, 79-85. [CrossRef]

84. Lopes, I.M.; Oliveira, P. Can a small city be considered a smart city? Procedia Comput. Sci. 2017, 121, 617-624. [CrossRef]

85. Yi, P.; Li, W.; Li, L. Evaluation and prediction of city sustainability using MCDM and stochastic simulation methods. Sustainability 2018, 10, 3771. [CrossRef]

86. Lv, Z.; Li, X.; Wang, W.; Zhang, B.; Hu, J.; Feng, S. Government affairs service platform for smart city. Future Gener. Comput. Syst. 2018, 81, 443-451. [CrossRef]

87. Ahmed, S.H.; Rani, S. A hybrid approach, Smart Street use case and future aspects for Internet of Things in smart cities. Future Gener. Comput. Syst. 2018, 79, 941-951. [CrossRef] 
88. Barns, S. Smart cities and urban data platforms: Designing interfaces for smart governance. City Cult. Soc. 2018, 12, 5-12. [CrossRef]

89. Kummitha, R.K.R.; Crutzen, N. How do we understand smart cities? An evolutionary perspective. Cities 2017, 67, 43-52. [CrossRef]

90. Fernandez-Anez, V.; Fernández-Güell, J.M.; Giffinger, R. Smart City implementation and discourses: An integrated conceptual model. The case of Vienna. Cities 2018, 78, 4-16. [CrossRef]

91. Khan, Z.; Pervez, Z.; Abbasi, A.G. Towards a secure service provisioning framework in a smart city environment. Future Gener. Comput. Syst. 2017, 77, 112-135. [CrossRef]

92. Zanella, A.; Bui, N.; Castellani, A.; Vangelista, L.; Zorzi, M. Internet of Things for Smart Cities. IEEE Internet Things J. 2014, 1, 22-32. [CrossRef]

93. Kourtit, K.; Nijkamp, P.; Arribas, D. Smart cities in perspective-A comparative European study by means of self-organizing maps. Innov. Eur. J. Soc. Sci. Res. 2012, 25, 229-246. [CrossRef]

94. Kourtit, K.; Nijkamp, P. Smart cities in the innovation age. Innov. Eur. J. Soc. Sci. Res. 2012, 25, 93-95. [CrossRef]

95. Söderström, O.; Paasche, T.; Klauser, F. Smart cities as corporate storytelling. City 2014, 18, 307-320. [CrossRef]

96. Anand, A.; Rufuss, D.D.W.; Rajkumar, V.; Suganthi, L. Evaluation of Sustainability Indicators in Smart Cities for India Using MCDM Approach. Energy Procedia 2017, 141, 211-215. [CrossRef]

97. Caragliu, A.; Bo, C.D.; Nijkamp, P. Smart Cities in Europe. J. Urban Technol. 2011, 18, 65-82. [CrossRef]

98. Albino, V.; Berardi, U.; Dangelico, R.M. Smart cities: Definitions, dimensions, performance, and initiatives. J. Urban Technol. 2015, 22, 3-21. [CrossRef] 